www.jmscr.igmpublication.org

Impact Factor (SJIF): 6.379

Index Copernicus Value: 79.54

ISSN (e)-2347-176x ISSN (p) 2455-0450

crossrefDOI: https://dx.doi.org/10.18535/jmscr/v6i11.68

Journal Of Medical Science And Clinical Research

\title{
Comparative Evaluation of two Different Fractionation Radiotherapy Schedules in Post Mastectomy Cases of Carcinoma Breast
}

\author{
Authors \\ Lalit Mohan Patel ${ }^{1}$, Laxmi Singotia ${ }^{2}$, Neha Kurmi Patel ${ }^{3}$ \\ ${ }^{1}$ Senior Resident, Dept. of Radiotherapy, NSCB Medical College, Jabalpur, India \\ ${ }^{2}$ Professor and Head, Dept. of Radiotherapy, NSCB Medical College, Jabalpur, India \\ ${ }^{3}$ Demonstrator, Dept. of pathology, NSCB Medical College, Jabalpur, India \\ Corresponding Author \\ Dr Laxmi Singotia \\ Email: singotialaxmi@gmail.com
}

\begin{abstract}
Background: Breast cancer is the most common malignant neoplasm and a leading cause of death in women worldwide. Radiation therapy for breast cancer is usually performed after surgery and is an integral component of breast-conserving therapy as well as after post mastectomy. The dose of radiation must be strong enough to ensure the eradication of cancer cells.

Objectives: To compare two different dose fractionation radiotherapy schedules in terms of: a) Loco regional control \& distant metastasis b) Acute and late radiation induced toxicities.

Methodology: Study was prospective and patients were divided into two groups-Group A and Group B. Group A- These patients were given Accelerated Hypofractionated Schedule (Study group) - 40 Gy/17 fractions/3.2weeks@2.35 Gy/fraction.Group B-These patients were given Conventional Fractionation Schedule (Control group) - 50 Gy/25 fractions/5 weeks @2 Gy/fraction.

Results: The median age of patients in both groups was 47 years, and patients were followed up till 18 months. Treatment time in group A and group B were 3.2 weeks and 5 weeks respectively. Patients of both the groups tolerated radiation well with locoregional control, distant metastasis and acute and late radiation reactions comparable in both the groups and there was no difference statistically $(p>0.05)$. Grade 1 acute radiation dermatitis was the most common reaction. Acute radiation dermatitis in group A and group B was $87 \%$ and $85 \%$, late reaction lymphedema was $17 \%$ and $15 \%$, locoregional failure was $12 \%$ and $15 \%$, distant metastasis was $7.5 \%$ and $5 \%$ respectively.

Conclusion: From the present study we concluded that patients in both the regimen groups tolerated the treatment well with non significant difference ( $p$ value $>0.05)$ in radiation toxicities. The overall treatment time (O.T.T.) in group A was significantly less in comparison to group B( $p$ value $<0.05)$.
\end{abstract}

\section{Introduction}

Breast cancer is the most common malignant neoplasm and a leading cause of death in women worldwide. $^{(1)}$ Breast cancer accounts for 1.8 million new cases and approximately 0.5 million deaths annually worldwide. ${ }^{(2)}$ It is the commonest cancer in urban Indian women and the second common cancer in the rural women next to cervical carcinoma. ${ }^{(3)}$ 
Incidence rates vary greatly worldwide from 19.3 per 100,000 women in Eastern Africa to 89.7 per 100,000 women in Western Europe. ${ }^{(4)}$

Breast cancer survival rates vary greatly worldwide, higher survival rate is found in developed countries with low survival rate in less developed countries. The global burden of breast cancer is expected to cross 2 million by the year 2030, with growing proportions from developing countries. Although age-standardised incidence rates in India are lower than in the United Kingdom (UK) (25.8 versus 95 per 100,000), mortality rates are nearly as high (12.7 versus 17.1 per 100,000 , respectively) as those of the UK. ${ }^{(5)}$ This trend of disease among the Indians can be explained mainly by the lack of early detection programmes, resulting in a high proportion of women presenting with late-stage disease, as well as by the lack of adequate diagnosis and treatment facilities. ${ }^{(6)}$

Management of breast cancer is undertaken by a multidisciplinary team based on national and international guidelines including surgery, chemotherapy, radiation therapy, hormonal therapy, immune therapy, Depending on clinical criteria (age, type of cancer, size, presence or absence of metastasis). ${ }^{(7)}$

In this study we compared two different dose fractionation radiotherapy schedules in post mastectomy cases of breast in terms of loco regional control and distant metastasis and acute and late radiation induced toxicities.

\section{Aims \& Objectives}

To compare two different dose fractionation radiotherapy schedules in terms of: a) Loco regional control \& distant metastasis b) Acute and late radiation induced toxicities.

\section{Material \& Methods}

This Prospective study was started carried after permission granted by ethical committee. 80 post mastectomy breast cancer patients were included in the study who received postoperative radiotherapy. Radiotherapy was given 3-4 weeks after surgery and completion of chemotherapy course (neoadjuvant or adjuvant). These patients were followed up for min. six to max. eighteen months and they were given hormonal treatment according to their hormonal receptor status in the follow-up period.

Patients were divided into two groups based on two treatment schedules i.e. study group and control groups with same number of patients in each group. These groups were:

Group A (study group)- These patients were given Accelerated Hypofractionated Schedule (Regimen-1) - 40 Gy/17 fractions/3.2 weeks @ $2.35 \mathrm{~Gy} /$ fraction

Group B (control group)- These patients were given Conventional Fractionation Schedule (Regimen-2) - 50 Gy/25 fractions/5 weeks @ 2 Gy/fraction.

For any suspected local recurrence found during examination, further confirmation was done by FNAC/Biopsy. All the necessary findings and data related to study were recorded and analysed by using software SPSS V 20.

\section{Results}

Total 80 patients were included in the study. Both groups had 40 patients each. In both the groups , patients were in the age group of $>30$ yrs to $<60$ years and majority of them were in their 4th decade of life. Both groups had more urban population. Both groups had more no. of patients with stage III disease i.e. $57.5 \%$ in study group and $62 \%$ in control group. Most common histological type was infiltrating ductal carcinoma $(97.5 \%)$. The results of treatment of 80 patients (40 in each group) were: In acute complications, acute radiation dermatitis was the most common complication in both the groups. In both the groups equal number of patients $(8 / 40=20 \%$ in each) developed acute dysphagia grade 1 . (Table 1)

In late complications, most common complication was grade 1 lymphedema in both the groups followed by grade 1 skin fibrosis, late dysphagia and dermatitis.(Table 2) 
In group A, local recurrence was $12.5 \%$ and in group B $15 \%$ and distant metastasis was found in $7.5 \%$ in group A and $5 \%$ in group B. So, there was no stastistically significant difference in terms of acute complications, late complications, local recurrence and distant metastasis. (Table 3 )

Table -1: Post mastectomy radiation therapy: acute reactions

\begin{tabular}{|l|c|c|c|c|c|c|}
\hline \multirow{2}{*}{ GRADES } & \multicolumn{2}{|c|}{$\begin{array}{c}\text { ACUTE RADIATION } \\
\text { DERMATITIS }\end{array}$} & \multicolumn{2}{c|}{ LYMPHEDEMA (ARM) } & \multicolumn{2}{c|}{ DYSPHAGIA } \\
\cline { 2 - 7 } & $\begin{array}{c}\text { GROUP A } \\
\mathrm{N}(\%)\end{array}$ & $\begin{array}{c}\text { GROUP B } \\
\mathrm{N}(\%)\end{array}$ & $\begin{array}{c}\text { GROUP A } \\
\mathrm{N}(\%)\end{array}$ & $\begin{array}{c}\text { GROUP B } \\
\mathrm{N}(\%)\end{array}$ & $\begin{array}{c}\text { GROUP A } \\
\mathrm{N}(\%)\end{array}$ & $\begin{array}{c}\text { GROUP B } \\
\mathrm{N}(\% 0\end{array}$ \\
\hline GRADE 0 & $3(7.5)$ & $5(12.5)$ & $33(82.5)$ & $31(77.5)$ & $28(70)$ & $26(65)$ \\
\hline GRADE I & $16(40)$ & $20(50)$ & $3(7.5)$ & $4(10)$ & $8(20)$ & $8(20)$ \\
\hline GRADE II & $20(50)$ & $15(37.5)$ & $3(7.5)$ & $2(5)$ & $4(10)$ & $6(15)$ \\
\hline GRADE III & $1(2.5)$ & $0(0)$ & $1(2.5)$ & $3(7.5)$ & $0(0)$ & $0(0)$ \\
\hline GRADE IV & $0(0)$ & $0(0)$ & $0(0)$ & $0(0)$ & $0(0)$ & $0(0)$ \\
\hline
\end{tabular}

Table -2: Post Mastectomy Radiation Therapy : Late Reactions

\begin{tabular}{|l|c|c|c|c|c|c|}
\hline \multirow{2}{*}{ GRADES } & \multicolumn{2}{|c|}{ SKIN FIBROSIS } & \multicolumn{2}{c|}{ LYMPHEDEMA (ARM) } & \multicolumn{2}{c|}{ DYSPHAGIA } \\
\cline { 2 - 7 } & $\begin{array}{c}\text { GROUP A } \\
\mathrm{N}(\%)\end{array}$ & $\begin{array}{c}\text { GROUP B } \\
\mathrm{N}(\%)\end{array}$ & $\begin{array}{c}\text { GROUP A } \\
\mathrm{N}(\%)\end{array}$ & $\begin{array}{c}\text { GROUP B } \\
\mathrm{N}(\%)\end{array}$ & $\begin{array}{c}\text { GROUP A } \\
\mathrm{N}(\%)\end{array}$ & $\begin{array}{c}\text { GROUP B } \\
\mathrm{N}(\% 0\end{array}$ \\
\hline GRADE 0 & $2(5)$ & $2(5)$ & $27(67.5)$ & $29(72.5)$ & $28(70)$ & $30(75)$ \\
\hline GRADE I & $22(55)$ & $25(62.5)$ & $7(17.5)$ & $6(15)$ & $10(25)$ & $8(20)$ \\
\hline GRADE II & $14(35)$ & $12(30)$ & $3(7.5)$ & $2(5)$ & $2(5)$ & $2(5)$ \\
\hline GRADE III & $2(5)$ & $1(2.5)$ & $3(7.5)$ & $3(7.5)$ & $0(0)$ & $0(0)$ \\
\hline GRADE IV & $0(0)$ & $0(0)$ & $0(0)$ & $0(0)$ & $0(0)$ & $0(0)$ \\
\hline
\end{tabular}

Table 3: Post Mastectomy Radiation Therapy: Status On Last Visit

\begin{tabular}{|l|c|c|}
\hline STATUS AT LAST FOLLOW UP & $\begin{array}{c}\text { GROUP A } \\
\mathrm{N}(\%)\end{array}$ & $\begin{array}{c}\text { GROUP B } \\
\mathrm{N}(\%)\end{array}$ \\
\hline No evidence of disease & $32(80)$ & $32(80)$ \\
\hline Recurrence of disease & $5(12.5)$ & $6(15)$ \\
\hline Distant metastasis & $3(7.5)$ & $2(5)$ \\
\hline Total no. of patient & 40 & 40 \\
\hline
\end{tabular}

The overall treatment time for Group A patients ranged from 21 to 24 (mean 22.5) days, while it was from 34 to 39 (mean 36.42) days for Group B patients $(\mathrm{p}$ Value $=0.0001)$. Statistically this difference is considered to be extremely significant.

$$
\begin{aligned}
& >\mathrm{P} \text { value }-0.0001 \\
& >\mathrm{T} \text { value }-47.69 \\
& >\text { Degree of freedom }(\mathrm{df})-98 \\
& >\text { Standard error of difference }-0.292
\end{aligned}
$$

\section{Discussion}

Surgery and radiotherapy are important for loco regional control in carcinoma breast. ${ }^{(8,9)}$ Surgical treatment is mandatory for cure of breast carcinoma $^{(10)}$ Various types of surgeries are practiced but Modified radical mastectomy is the most common form of mastectomy performed nowadays in developing countries because of disease presentation in advanced stage. ${ }^{(8)}$ This was the operation done in all our patients included in the present study. Modified radical mastectomy includes removal of breast with axillary nodal dissection but with preservation of pectoralis major muscle. ${ }^{(10)}$ Radiation after surgery decreases loco-regional recurrence. ${ }^{(11)}$

There is no general agreement in literature regarding dose of radiation therapy which should be delivered to a patient after mastectomy. The doses, ranging from $32.5 \mathrm{~Gy} / 3$ weeks to $60 \mathrm{~Gy} / 10$ to 14 weeks have been given.(51-55). Data from randomized trials regarding hypofractionation for treatment of women with breast cancer, confirm the safety and efficacy of schedules using fraction sizes of around $3 \mathrm{~Gy}$, provided the correct downward adjustments to total dose are made. ${ }^{(12)}$ Hypofractionated radiation therapy offers the advantage of a more efficient and productive use 
of radiotherapy departments resources; whether machine time, staffing of treatment units, lower expenses in addition to far better patients convenience. ${ }^{(13)}$

On the other hand, hypofractionation, with larger radiation dose per fraction increases the possibility of late normal tissue damage. ${ }^{(14,15)}$

However, the linear-quadratic model predicts that the normal tissue toxicity is not increased when the fraction dose is modestly increased and the total dose is reduced. ${ }^{(12)}$

This is confirmed by results of many trials where hypofractionated radiotherapy protocols are as effective as the conventional radiation of $50 \mathrm{~Gy}$ in 25 fractions, regardless of disease stage or type of breast surgery. ${ }^{(16,17)}$

Although the safety and efficacy of hypofractionation have been confirmed by a number of clinical trials in western countries, there remains much controversy especially at the level of the understanding of the underlying radiobiological mechanisms. The tool most commonly used for quantitative predictions of dose / fractionation dependencies in radiotherapy is the mechanistically-based linear-quadratic (LQ) model. ${ }^{(17,18,19)}$ In our study, majority of the patients were of the age group 41-50 years. The mean age of cases in group A patients was 48.9 years while for group B patients, it was 47.6 years. In concurrence with this study, 48 and 50 years were the mean age of patients in group $\mathrm{A}$ and group B respectively in the study by Abhilash GH et $\mathrm{al}^{(2)} \mathrm{Also}$ the study done by El- Sayed et $\mathrm{al}^{(20)}$ show no significant difference between the mean age of 2 groups.

In the present study, majority of the patients were from urban areas in both the groups. This is due to the changing lifestyle, late marriages in urban areas.

\section{Radiation toxicities}

In our study, patients were treated by two regimens- conventional and accelerated hypofractionated. Patients in both the regimen groups tolerated the treatment well with non significant difference ( $\mathrm{p}$ value $>0.05$ ) in acute and late radiation toxicities.

Multiple randomized trials have been done that have compared hypofractionated radiation therapy with conventional radiation therapy and demonstrated no difference in late radiation morbidity. ${ }^{(21-25)}$ Earliest report of fractionation in PMRT was by Kim et al, ${ }^{(26)}$ who compared four different fractionation schedules. They found no difference in acute reactions in all four fractionation schedules.

Studies done by Pinitpatcharalert A, et $\mathrm{al}^{(27)}$ and Kumbhaj PR et $\mathrm{al}^{(7)}$ show concordance with the present study where no difference of toxicities was found between the two groups.

\section{Locoregional control and distant metastasis}

During the follow up period, local recurrence was seen in 5/40 patients in group A (3 patients showed chest wall recurrence and 2 patients showed nodal recurrence).In group B, 6/40 (3 patients showed chest wall recurrence and 3 patients showed nodal recurrence).

Metastasis to distant sites like brain, lungs and liver was seen in few patients. In group A, 3/40 patients $(7.5 \%)$ and in group B, 5/40(5\%) showed distant metastasis. Lung was noted to be the commonest site for the metastasis. Both the groups showed no significant difference in locoregional control $(\mathrm{p}$ value $=0.7)$ and distant metastasis $(\mathrm{p}$ value $=0.5)$

Kumbhaj PR et $\mathrm{al}^{(7)}$ did a study of post mastectomy chest wall irradiation in carcinoma breast patients. Their study showed chest wall recurrence, axillary failure and distant metastasis as 5/50 (10\%), 3/50 (6\%) and; $16 / 50(32 \%)$ in group A versus $3 / 54$ (5.6\%), 4/54 (7\%) and 15/54 (28\%) in Group B.

Main side effects noted were reversible cutaneous reactions, difficulty in swallowing. These results are comparable to our study. Meta-analyses and Randomized Controlled Trials (at least 18RCTs) of loco regional PMRT have consistently demonstrated that PMRT reduces the risk of loco regional failure by approximately two-thirds. ${ }^{(21,25)}$ 


\section{Conclusion}

In present study the justification of giving hypofrationation has been proven because acute and late radiation reactions were comparable and Locoregional recurrence and distant metastasis was also comparable. Since most of the population of breast cancer belong to urban region it saves the time of working women as well as decreases the workload of hospitals due to scarcity of resources and long waiting list of radiation. It has also increased the patient compliance and has given the reliable alternative of radiation in patients.

\section{References}

1. Alam Md S, Perween R, Siddiqui AS. Accelerated Hypofractionated Radiation in Carcinoma Breast. Arch Cancer Res. 2016, 4:1.

2. Abhilash GH, Dhull AK, Atri R, et al. Comparison of hypofractionated radiation therapy versus conventional radiation therapy in post mastectomy breast cancer. J. Evid. Based Med. Healthc. 2016; 3(26), 1177-1181.

DOI: 10.18410/jebmh/2016/270

3. Sood N, Nigam JS, Yadav $\mathrm{P}$ et al. Comparative Study of Cytomorphological Robinson's Grading for Breast Carcinoma with Modified Bloom-Richardson Histopathological Grading. Pathology Research International, vol. 2013, Article ID $146542, \quad 5$ pages, 2013. doi:10.1155/2013/146542

4. Anderson BO et al. (2008). Guideline implementation for breast healthcare in low-income and middle-income countries: overview of the Breast Health Global Initiative Global Summit 2007. Cancer, 113, 2221-43.

5. Gupta A, Shridhar K, Dhillon PK. A review of breast cancer awareness among women in India: Cancer literate or awareness deficit?. European journal of cancer. 2015 Sep 1;51(14):2058-66
6. Coleman MP et al. (2008). Cancer survival in five continents: a worldwide populationbased study (CONCORD). Lancet Oncol, 9, 730-56.7

7. Kumbhaj PR, Sharma R, Saini PK, Patel PR. Study of two different dose fractionation schedules of post mastectomy chest wall irradiation in carcinoma breast patients. Int J Med Sci Public Health. (2013), [cited November 03, 2015]; 2(4): $1001-$

1005.doi:10.5455/ijmsph.2013.040820131 7

8. Carlos A, Perez CA, Taylor ME. Breast: Stage Tis, T1 and T2 tumors. In: Perez CA, ed. Principles and practice of radiation oncology. Philadelphia: Lippincott - Raven, 1999;1269-1396.9

9. Will BP, LePetit C, Berthelot JM, Tomiak EM, Verma S. Diagnostic and therapeutic approaches for nonmetastatic breast cancer in Canada, and their associated costs. $\mathrm{Br} \mathrm{J}$ Cancer. 1999;79,1428-143610

10. Baker RR. The clinical management of primary breast cancer. In Baker RR, ed. Current trends in management of breast cancer. Baltimore: Cassell and Collier Macmillian, 1977;77-12311

11. Chapman JW, Fish EB, Link MA. Competing risks analyses for recur-rence from primary breast cancer. Br J Cancer. 1999;79:1508-151312

12. Yarnold J, Bentzen SM, Coles C, Haviland J (2011) Hypofractionated whole-breast radiotherapy for women with early breast cancer: myths and realities. Int $\mathbf{J}$ RadiatOncolBiolPhys 79: 1-9.13

13. Taher AN, El-Baradie MM, Essa H, Zaki O, Ezzat S, et al. (2004) Hypofractionation versus conventional fractionation radiotherapy after conservative treatment of breast cancer: early skin reactions and cosmetic results. J Egypt NatlCancInst 16: 178-187.14 
14. Archambeau JO, Pezner R, Wasserman T (1995) Pathophysiology of irradiated skin and breast. Int J RadiatOncolBiolPhys 31: 1171-1185.15

15. Awwad HK (1990) Dose-Time-Volume relationships in normal tissue to radiation. In Radiation Oncology: Radiobiological and Physiological Prespective. Kluwer Academic, Dordecht, Boston, London, 129-187.16

16. Deantonio L, Gambaro G, Beldì D, Masini L, Tunesi S, et al. (2010) Hypofractionated radiotherapy after conservative surgery for breast cancer: analysis of acute and late toxicity. RadiatOncol 5: 11217

17. Owen JR, Ashton A, Bliss JM, Homewood J, Harper C, et al. (2006) Effect of radiotherapy fraction size on tumour control in patients with early-stage breast cancer after local tumour excision: longterm results of a randomised trial. Lancet Oncol 7: 467-47118

18. Fowler JF (1989) The linear-quadratic formula and progress in fractionated radiotherapy. Br J Radiol 62: 679-69419

19. Sachs RK, Hahnfeld P, Brenner DJ (1997) The link between low-LET doseresponse relations and the underlying kinetics of damage production/repair /misrepair. Int J RadiatBiol 72: 351-374.20

20. El-Sayed MI, Abdel-Wanis ME (2012) Comparison of Hypofractionated and Conventional Radiotherapy Protocols in Breast Cancer Patients: A Retrospective Study. J Cancer SciTher 4: 158-163. doi: 10.4172/1948-5956.100013221

21. Gorey KM, Luginaah IN, Holowaty EJ, Fung KY, Hamm C. Wait times for surgical and adjuvant radiation treatment of breast cancer in Canada and the United States: greater socioeconomic inequity in America. Clin Invest Med. 2009, 32:E239E24923

22. Kaufmann M, Morrow M, Von Minckwitz G, Harris JR. Locoregional treatment of primary breast cancer: consensus recommendations from an International Expert Panel. Cancer. 2010, 116:1184119123

23. Veronesi U, Orecchia R, Luini A, Galimberti V, Zurrida S, Intra $M$ et al. Intraoperative radiotherapy during breast conserving surgery: a study on 1,822 cases treated with electrons. Breast Cancer Res Treat. 2010;124:141-151.24

24. Vaidya JS, Joseph DJ, Tobias JS, Bulsara M, Wenz F, Saunders C et al. Targeted intraoperative radiotherapy versus whole breast radiotherapy for breast cancer (TARGIT-A trial): an international, prospective, randomised, non-inferiority phase 3 trial. Lancet. 2010;376:91-102.25

25. Beitsch PD, Shaitelman SF, Vicini FA. Accelerated partial breast irradiation. J Surg Oncol. 2011; 103:362-368.26

26. Forrest AP, Stewart HJ, Everington D, et al. Randomised controlled trial of conservation therapy for breast cancer: 6year analysis of the Scottish trial. Scottish Cancer Trials Breast Group. Lancet 1996;348(9029):708-713.27

27. Pinitpatcharalert A et al. A retrospective study comparing hypofractionated radiotherapy and conventional radiotherapy in postmastectomy breast cancer. J Med Assoc Thai. 2011 March; 94 (Suppl 2): S94-102. 